\title{
Electrochemical evaluation of total antioxidant capacity of beverages using a purine-biosensor
}

\author{
M. Fátima Barroso, C. Delerue-Matos, M.B.P.P. Oliveira
}

\begin{abstract}
In this paper, it was evaluated the total antioxidant capacity (TAC) of beverages using an electrochemical biosensor. The biosensor consisted on the purine base (guanine or adenine) electro-immobilization on aglassy carbon electrode surface (GCE). Purine base damage was induced by the hydroxyl radical gener- ated by Fenton-type reaction. Five antioxidants were applied to counteract the deleterious effects of the hydroxyl radical. The antioxidants used were ascorbic acid, gallic acid, caffeic acid, coumaric acid and resveratrol. These antioxidants have the ability to scavenger the hydroxyl radical and protect the guanine and adenine immobilized on the GCE surface. The interaction carried out between the purine- base immobilized and the free radical in the absence and presence of antioxidants was evaluated by means of changes in the guanine and adenine anodic peak obtained by square wave voltammetry (SWV). The results demonstrated that the purine-biosensors are suitable for rapid assessment of TAC in beverages.
\end{abstract}

Key w ords: Purine bases, Total antioxidant capacity (TAC), Ascorbic acid, Phenolic acid, Reactive oxygen species (ROS), Hydroxyl radical (OH.), Biosensor

\section{Introduction}

In recent years, the interest for DNA-based diagnostic tests has been growing. The development of systems allowing DNA detection is motivated by applications in many fields: DNA diagnostics, fast detection of biological warfare agents and forensic applications. Detection of genetic mutations at the molecular level opens up the possibility of performing reliable diagnostics even before any symptom of a disease appears (Sassolas, Leca-Bouvier, \& Blum, 2008). Reactive oxygen species (ROS) produced in living organisms by normal metabolism and by exogenous sources such as carcinogenic compounds and ionising radiations induce oxidative DNA damage producing a variety of modifications at DNA level including base and sugar lesions, strand breaks, DNA-protein cross-link and base-free sites (Dizdaroglu, Jaruga, Birincioglu, \& Rodriguez, 2002; Mello, Hernandez, Marrazza, Mascini, \& Kubota, 2006; Vertuani, Angusti, \& Manfredini, 2004). However, the mammalian cells have employing a complex endogenous defence system to repair the damaged DNA through specific enzymes such as superoxide dismutase, catalase, peroxidase, myeloperoxidase that are involved in the base excision repair (Cadet, Douki, Gasparutto, \& Ravanat, 2003). Beyond this endogenous system, the living organisms also use exogenous antioxidant compounds. An antioxidant is any substance that when present at low concentration compared to those of an oxidizable substrate significantly delays, inhibits or prevents oxidation of that substrate in a chain reaction, therefore, appears to be very important in the prevention of many diseases (Frankel, 2007; Halliwell, Gutteridge, \& Cross, 1992; Mello $\&$ Kubota, 2007). Antioxidants may delay or inhibit the chain initiation, propagation and termination by reaction with a peroxyl radical (ROO) or alkoxyl radical ( $\mathrm{RO}$ ) resulting in a lesser reactive radical (A). In the inhibited oxidation, termination occurs through the reaction of $\mathrm{ROO}$ and $\mathrm{RO}$ with a chain-breaking phenolic antioxidant (AH), by interrupting the chain reaction by hydrogen transfer to produce a phenoxy radical (A) (Eqs. (1) and (2)) that is too stable to continue the chain by reaction. The antioxidant radical can either react again with the ROO (Eq. (3)) and RO (Eq. (4)) to form a stable peroxide or hydroxyl or react with another antioxidant radical to form a dimer (Eq. (5)) (Frankel, 2007):

$$
\begin{aligned}
& \mathrm{ROO}^{*}+\mathrm{AH} \rightarrow \mathrm{ROOH}+\mathrm{A}^{*} \\
& \mathrm{RO}^{*}+\mathrm{AH} \rightarrow \mathrm{ROH}+\mathrm{A}^{*} \\
& \mathrm{ROO}^{*}+\mathrm{A}^{*} \rightarrow \mathrm{ROOA} \\
& \mathrm{RO}^{*}+\mathrm{A}^{*} \rightarrow \mathrm{ROA} \\
& \mathrm{A}^{*}+\mathrm{A}^{*} \rightarrow \mathrm{A}-\mathrm{A}
\end{aligned}
$$


Increasing intake of dietary antioxidant may help to maintain an adequate antioxidant status and, therefore, the normal physiological functions of a living system. Some functional foods, vegetables, fruits, whole-grain cereals, wine and infusions are good sources of exogenous antioxidants (Ignat, Volf, \& Popa, 2011). These foodstuff and beverages include in its composition exogenous antioxidants such as vitamins (A, E and C), phenolic compounds (gallic acid, caffeic acid, ferulic acid, $p$-coumaric acid and sinapic acid), flavonoids (quercetin and rutin), minerals (selenium and zinc) or proteins (transferrin, ceruloplasmin and albumin). Ascorbic acid is a c-lactone synthesized by plants and many animals (except primates). This powerful exogenous antioxidant is a water-soluble vitamin, and plays a key role in the protection against biological oxidation processes. Indeed, ascorbic acid is a good scavenger of free radicals acting as a reducing agent by donation of a one electron producing the semi-dehydroascorbate radical. It justifies its association to protection against cancer agents by the prevention of formation of carcinogens precursors' compound (Lee, Davis, Rettmer, \& Lable, 1988; Mello \& Kubota, 2007; Smirnoff, 2000). Phenolic compounds (originated from vegetables) also present antioxidant activity. In general, the antioxidant activity of the phenolics-derived compounds is determined by its ideal chemical structure in terms of some properties such as free-radical scavengers or chain breakers agents. It also, the fact of the resulting antioxidant-derived radical, namely phenoxy radical is relatively stable due to the resonance delocalization and lack of suitable sites for attack by molecular oxygen. The last property, the transition metal-chelating potential, in special iron and copper supports the role of polyphenols as preventive antioxidants in terms of inhibiting transition metal-catalysed free radical formation (Soobrattee, Neergheen, Ramma, Aruoma, \& Bahorun, 2005; Thavasi, Leong, \& Bettens, 2006).

Several methods have been proposed for the evaluation of the total antioxidant capacity (TAC) in biological and food samples. These methodologies are based on UV-vis spectrometry, chemiluminescence, fluorimetry (Sanchez-Moreno, 2002), chromatography (Jaitz et al., 2010) and electrochemistry techniques (Piljac-Z egarac, Valek, Stipc evic', \& Martinez, 2010). Electrochemical DNA-based have been developed in order to assess the antioxidant capacity (Mello \& Kubota, 2007). These biosensors were based on the dsDNA (double-stranded DNA) (Mello et al., 2006), $\mathrm{dA}_{21}$ (deoxyadenylic acid oligonucleotide) ((Barroso, Delerue-Matos, \& Oliveira, 2011a) immobilization on the electrode surface, as oxidation target and a Fenton-type reaction were used for (hydroxyl) $\mathrm{OH}^{-}$generation (Eq. (6)):

$$
\mathrm{Fe}^{2+}+\mathrm{H}_{2} \mathrm{O}_{2} \rightarrow \mathrm{Fe}^{3+}+\mathrm{OH}^{-}+\mathrm{OH}^{-}
$$

Hydroxyl radicals interact with DNA bases inducing damage.

In this work, the TAC of flavoured waters was evaluated using a purine-based biosensor. This purine-based biosensor consisted on the electro-deposition of purine bases (guanine and adenine) on a glassy carbon electrode (GCE) surface. The biosensor was damaged by the hydroxyl radical according the procedure of Kamel and collaborators (Kamel, Moreira, Delerue-Matos, \& Sales, 2008). The influence of five antioxidants on the scavenger free radical activity was studied. The antioxidants used were ascorbic acid, and the following phenolic acids, gallic acid, caffeic acid, coumaric acid and resveratrol (polyphenol). The protective effect of these five antioxidants on the purine bases was observed. Square wave voltammetry (SWV) was the electroanalytical technique used to relate the extent of oxidative damage carried out by the hydroxyl radical and the protective role made by antioxidants.

\section{Material and methods}

\subsection{Chemicals}

Guanine (G-0381), adenine (A-8626), iron (II) sulphate heptahydrate, hydrogen peroxide $(100 \% \mathrm{w} / \mathrm{v})$, gallic acid, resveratrol were purchased from Sigma. Caffeic acid was from Fluka, L(+) ascorbic acid and $p$-coumaric were acquired from Riedel-de-Haën. Chemicals were Merck pro-analysis grade and were used as received. Guanine stock solution $\left(1 \mathrm{~g} \mathrm{~L}^{-1}\right)$ was prepared by dissolving an amount of this solid in $0.1 \mathrm{~mol} \mathrm{~L}^{-1}$ of $\mathrm{NaOH}$ and dilution in phosphate buffered saline (PBS) at $\mathrm{pH}$ 7.4. Stock solution of $1 \mathrm{~g} \mathrm{~L}^{-1}$ of adenine was prepared in PBS pH 7.4 and stored at $+4^{\circ} \mathrm{C}$.

Working standard solution (ascorbic acid, gallic acid, caffeic acid and coumaric acid) were prepared daily and immediately before measurements by dissolving an amount of the solid standard in water until the desired concentration. In order to dissolve the resveratrol antioxidant, $1 \mathrm{mg}$ of this compound was dissolved in ethanol and then volume was adjusted to $50 \mathrm{~mL}$ with water.

Hydroxyl radical was generated by mixing $\mathrm{Fe}^{2+}:$ EDTA: $\mathrm{H}_{2} \mathrm{O}_{2}$ $\left(0.20: 0.40: 8 \mathrm{mmol} \mathrm{L}^{-1}\right)$ in the molar ratio of 1:2:40. Mello and collaborators (Mello et al., 2006) reported that when an excess of hydrogen peroxide is added in the reaction a high DNA damage is obtained. EDTA was added for solubility reasons. All solutions were prepared with water purified with a Direct-Q (Millipore) system.

\subsection{Apparatus}

Square wave voltammetry (SWV) was performed with an Autolab PSTAT 10 potentiostat controlled by GPES software (EcoChemie, The Netherlands). A conventional three electrode cell was used, which includes glassy carbon electrode (GCE) $\left(0.07 \mathrm{~cm}^{2}\right)$ as working electrode, a glassy carbon counter electrode and a $\mathrm{Ag}|\mathrm{AgCl}| \mathrm{KCl}_{\text {sat }}$ reference electrode to which all potentials are referred. GCE was mechanically polished using a polishing kit (Metrohm 6.2802.010) first with $\mathrm{c}-\mathrm{Al}_{2} \mathrm{O}_{3}(0.0151 \mathrm{~m})$ until a shining surface was obtained and after with only water. After this step the GCE was treated by applying a fixed potential of $+1.7 \mathrm{~V}$ for $30 \mathrm{~s}$ in PBS $\mathrm{pH}$ 4.8. This initial conditioning step improves the resolution of the analytical signal because the application of high potentials in acidic medium increases the hydrophilic properties of the electrode surface through the introduction of oxygenated functionalities (Mello et al., 2006; Rice, Galus, \& Adams, 1983).

\subsection{Voltammetric procedure}

Unless otherwise mentioned, all experiments consisted of three steps: (i) guanine or adenine electro-immobilization on the GCE, (ii) damage of purine bases by the immersion of purine-based GCE on the hydroxyl radical, and study the effect of the presence of antioxidants in the reactive system; (iii) detection and measurement of the peak current of adenine or guanine in a PBS at $\mathrm{pH}$ 7.4.

Purine base (adenine or guanine) immobilization was performed by the application of an adsorptive accumulation step. For that, the activated GCE was immersed in PBS pH 4.8 containing $10 \mathrm{mg} \mathrm{L}^{-1}$ of adenine or $3 \mathrm{mg} \mathrm{L}^{-1}$ of guanine and it was applied a positive potential of $+0.4 \mathrm{~V}$ for $180 \mathrm{~s}$, after this the electrode was washed with water (Scheme 1). For the purine bases biosensor preparation procedure (cleaning and immobilization step) it was used the conditions optimised in previous works (Kamel et al., 2008; Mello et al., 2006). 

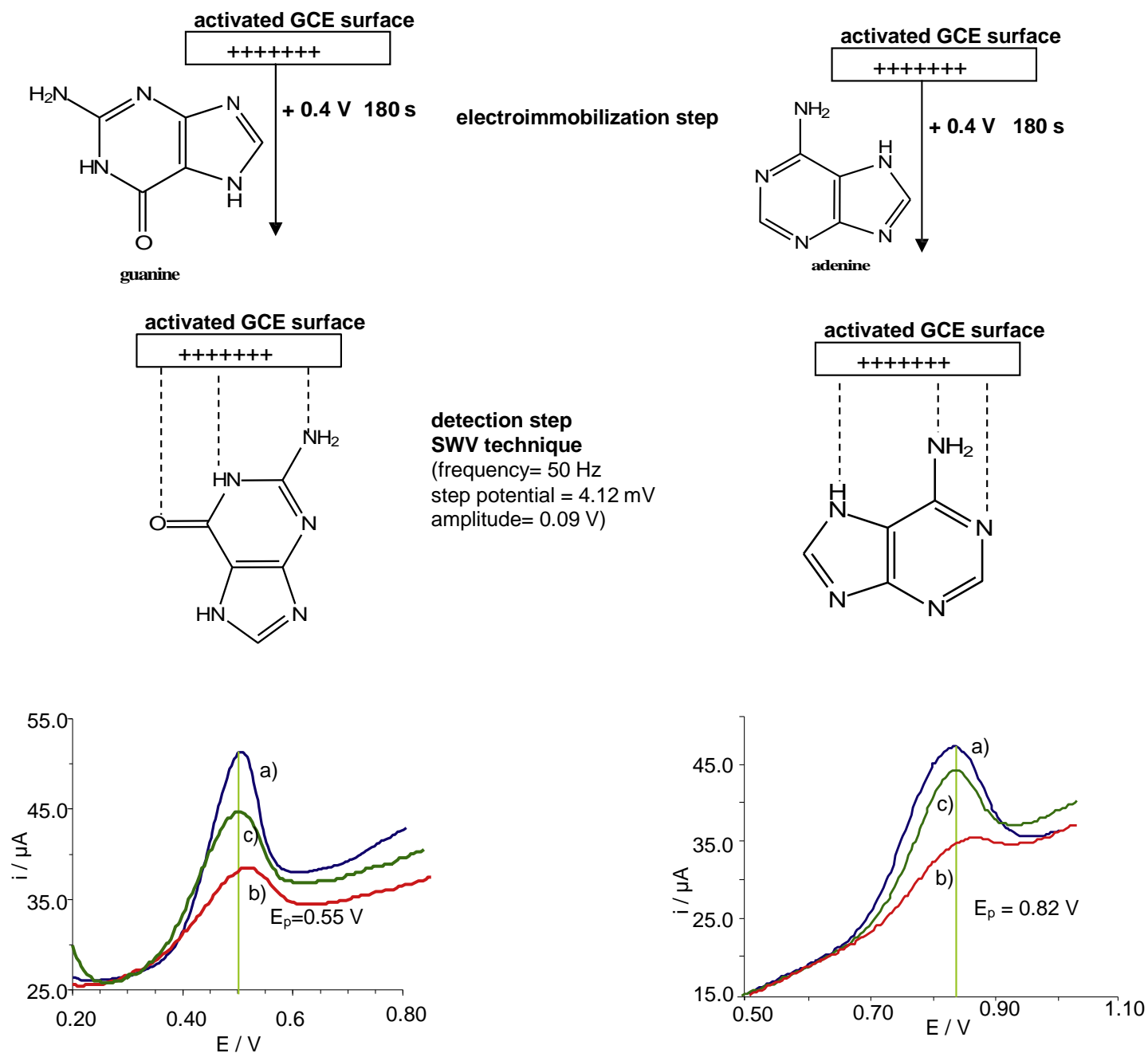

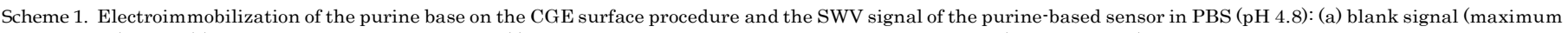
peak current); after (b) immersion in hydroxyl radical; (c) immersion in hydroxyl radical with an antioxidant (ascorbic acid).

Purine base damage was carried out by immersing the biosensor in a freshly prepared Fenton solution in the absence or in the presence of antioxidant in PBS pH 7.4. After a fixed period of reaction time, the purine-based biosensor was rinsed with water and immediately immersed in PBS ( $\mathrm{pH} 4.8$ ) to carry out the SWV between +0.2 and $+1.4 \mathrm{~V}$ (frequency $50 \mathrm{~Hz}$, step potential $4.12 \mathrm{mV}$ and amplitude $0.09 \mathrm{~V}$ ). The peak current of guanine and adenine obtained was used as a detection signal. For the electrochemical studies it was considered that the maximum signal current obtained was for the purine base signal without damage neither antioxidant effect (Scheme 1).

\subsection{Samples}

Thirty-nine water samples corresponding to ten different brands were purchased in several supermarkets in the North of Portugal and stored in the dark at $+4{ }^{\circ} \mathrm{C}$. Each brand (still or sparkling, mineral or spring water) had different flavours and aromas. The natural water of each brand was also used as control. Sonication (30 min) was used to eliminate gas from the sparkling water samples. The labels on the water bottles indicate the nutrient information, namely the presence of fruit juice, vitamins, sweeteners and preservatives.

Six liquid flavours used in the formulation of some water brands, provided by a producer, were also analysed. The flavours used corresponded to different fruit aromas, such as lime, tangerine, strawberry, lemon, apple and gooseberry. These flavours had no description about their chemical or aroma composition, but were known to be present in the flavoured waters used in this study.

\subsection{TAC measurement on beverages}

The purine-based biosensor was applied to the determination of TAC on flavour and flavoured waters. For the measurement of TAC in beverages, a volume of flavoured water or flavour were diluted in PBS to a final volume of 50011 . Then, the purine-based GCE was immersed in the solution and a freshly prepared hydroxyl radical was added for $120 \mathrm{~s}$. After this period of time the biosensor was washed and immersed in PBS buffer to measure the oxidation peak current of guanine and adenine. Ascorbic acid, gallic acid, caffeic acid, coumaric acid and resveratrol were the working standard antioxidants used to study the protective effect made by the antioxidant on the free-radical scavenging and to carry out the linear calibrations studies. Measurements were made at least three time and all results were expressed as mean \pm standard deviation.

\section{Results and discussion}

Previous studies reported in the literature indicate the oxidative damage of dsDNA (Mello et al., 2006), $\mathrm{dA}_{21}$ (Barroso, de-los-SantosÁlvarez et al., 2011a, 2011b) and purine bases (Kamel et al., 2008) 
induced by the hydroxyl radical generated by the Fenton solution. Hydroxyl radical $(\mathrm{OH})$ is one of the most reactive radical species that induce lesions in DNA. This ROS cause cell injury when is generated in excess or the cellular antioxidant defence is impaired. When hydroxyl radical is generated adjacent to DNA, it attacks both deoxyribose sugar and the purine and pyrimidine bases resulting intermediates radicals, which are the immediate precursors for DNA base damage (Jaruga \& Dizdaroglu, 1996). In order to study the protective effect promoted by antioxidants on the deactivation of the hydroxyl radical and consequently protect the purine bases from the oxidative damage, the purine-based biosensor was placed in a PBS $\mathrm{pH}$ 4.8 in presence of an antioxidant and hydroxyl radical during $120 \mathrm{~s}$. Next the biosensor was rinsed with water and a SWV was made from +0.2 to $+1.4 \mathrm{~V}$. Fig. 1 shows the performance of the purine-based biosensor in the presence of antioxidants $\left(0.5 \mathrm{mg} \mathrm{L}^{-1}\right.$ of ascorbic acid, gallic acid, caffeic acid, coumaric acid and resveratrol) and the hydroxyl radical $\left(\mathrm{Fe}^{2+}:\right.$ EDTA: $\mathrm{H}_{2} \mathrm{O}_{2} ; 0.1: 0.2: 4.0 \mathrm{mmol} \mathrm{L}^{-1}$ for the guanine biosensor and $\mathrm{Fe}^{2+}:$ EDTA: $\mathrm{H}_{2} \mathrm{O}_{2} ; 0.2: 0.4: 8.0 \mathrm{mmol} \mathrm{L}{ }^{-1}$ for the adenine biosensor). Formula 1 was used to calculate the purine base signal. effect on the purine base carried out by the antioxidants ranged from $47 \%$ to $79 \%$. Using the guanine-biosensor the lowest values were found for caffeic and coumaric acid, 47.6 and $49.1 \%$, respectively. The highest values was obtained for resveratrol $(74.6 \%)$ followed by gallic acid (72.0\%) and ascorbic acid (62.8\%). Using the adenine-biosensor the protective effective of the antioxidants ranged from $60 \%$ to $79 \%$. The highest values was observed for the resveratrol antioxidant $(79.1 \%)$ followed by gallic acid $(77.7 \%)$ and caffeic acid (73.6\%). The lowest values were found for ascorbic acid (60.4\%) and coumaric acid (61.9\%). Using a DNA-based biosensor, ascorbic acid $\left(0.51 \mathrm{~mol} \mathrm{~L}^{-1}\right)$ presented a protective role of $58 \%$ against the hydroxyl radical, and a concentration of $101 \mathrm{~mol} \mathrm{~L}^{-1}$ of ascorbic acid presented a protective role of $53.8 \%$ against the superoxide radical (Barroso, de-los-Santos-Álvarez et al., 2011a, 2011b).

The protection action mode of antioxidants may involve multiple mechanisms, depending on the source material and, possible presence of synergists and antagonists. In general, the antioxidant activity of ascorbic acid and phenolics-derived compounds is related to reducing properties as hydrogen or electron-donating

Purine base signalð\% $\%$ $1 / 4 \frac{i_{p} \text { measured after purine base damage with hydroxyl radicaloor in the presence of an antioxidantP }}{i_{p} \text { measured when no damage was done gmaximum expected value } \mathrm{p}} 100$

To perform this electrochemical study all current peaks were compared with the signal current obtained with the non damaged adenine and guanine bases (blank signal). Purine bases of DNA measured in SWV presented two oxidation peaks at around $+0.55 \mathrm{~V}$ and $+0.82 \mathrm{~V}$ corresponding, respectively, to guanine and adenine oxidation peak (Scheme 1a and b). Hydroxyl radical had the ability to produce $61.4 \%$ and $55.2 \%$ of damage in guanine and adenine base, respectively (Fig. 1). Other free radicals had also the capacity to induce oxidative damage on the purine bases. It was verified that superoxide radical produce from about $64 \%$ of damage on guanine-based biosensor (Barroso, de-los-SantosÁlvarez et al., 2011a) and $85 \%$ on the $\mathrm{dA}_{21}$ (Barroso, Delerve-Matos, \& Oliveira, 2011a) while the sulphate radical produced $61 \%$ of damage on guanine-based biosensor (Barroso, Delerue-Matos, \& Oliveira, 2011b). When it was added an antioxidant $\left(0.5 \mathrm{mg} \mathrm{L}^{-1}\right)$ in the reactive system a less decrease of the anodic current of guanine and adenine was recorded. It was observed a protective agents, which is determined to its reduction potential (Buettner, 1993; Mello \& Kubota, 2007; Rice-Evans, 2001).

\subsection{Optimisation of the experimental conditions}

In order to evaluate the TAC on beverages, some parameters concerning the damaging reaction (iron concentration and reaction time between hydroxyl radical) at a fixed time reaction were implemented in order to achieve the maximum purine base of DNA effect, but without a complete damage (non-zero $i_{p}$ ). The level of purine bases damage was evaluated as function of the variation of the concentration of $\mathrm{Fe}^{2+}$ keeping constant the molar ratio $\mathrm{Fe}^{2+}$ :EDTA: $\mathrm{H}_{2} \mathrm{O}_{2}$ used (1:2:40) (Mello et al., 2006). $\mathrm{Fe}^{2+}$ concentration was studied between $5.01 \mathrm{~mol} \mathrm{~L}^{-1}$ and $1.0 \mathrm{mmol} \mathrm{L}^{-1}$. A range of $19-60 \% \mathrm{de}^{-}$ crease in the $i_{p}$ of guanine and adenine immobilized on the GCE surface was observed over the $\mathrm{Fe}^{2+}$ concentration studied. When it was used the adenine-biosensor, a $52 \%$ decrease on the $i_{p}$ was recorded

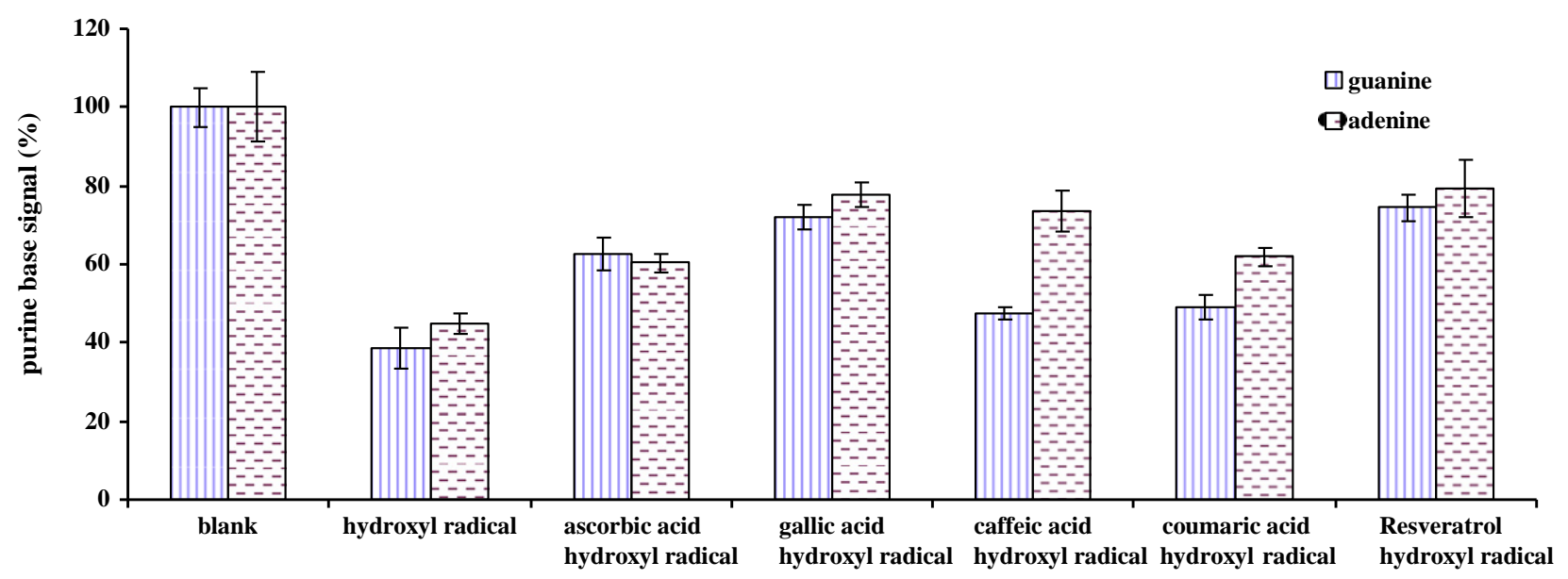

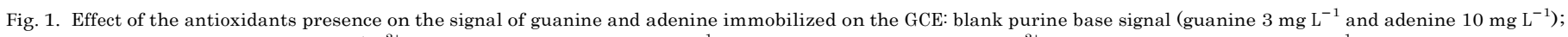

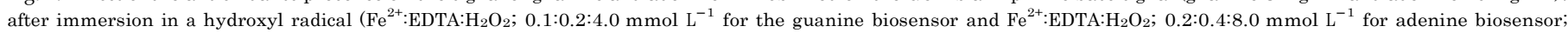
$120 \mathrm{~s}$ ) immersion in hydroxyl radical with five different antioxidants $\left(0.50 \mathrm{mg} \mathrm{L}^{-1}\right)$. 


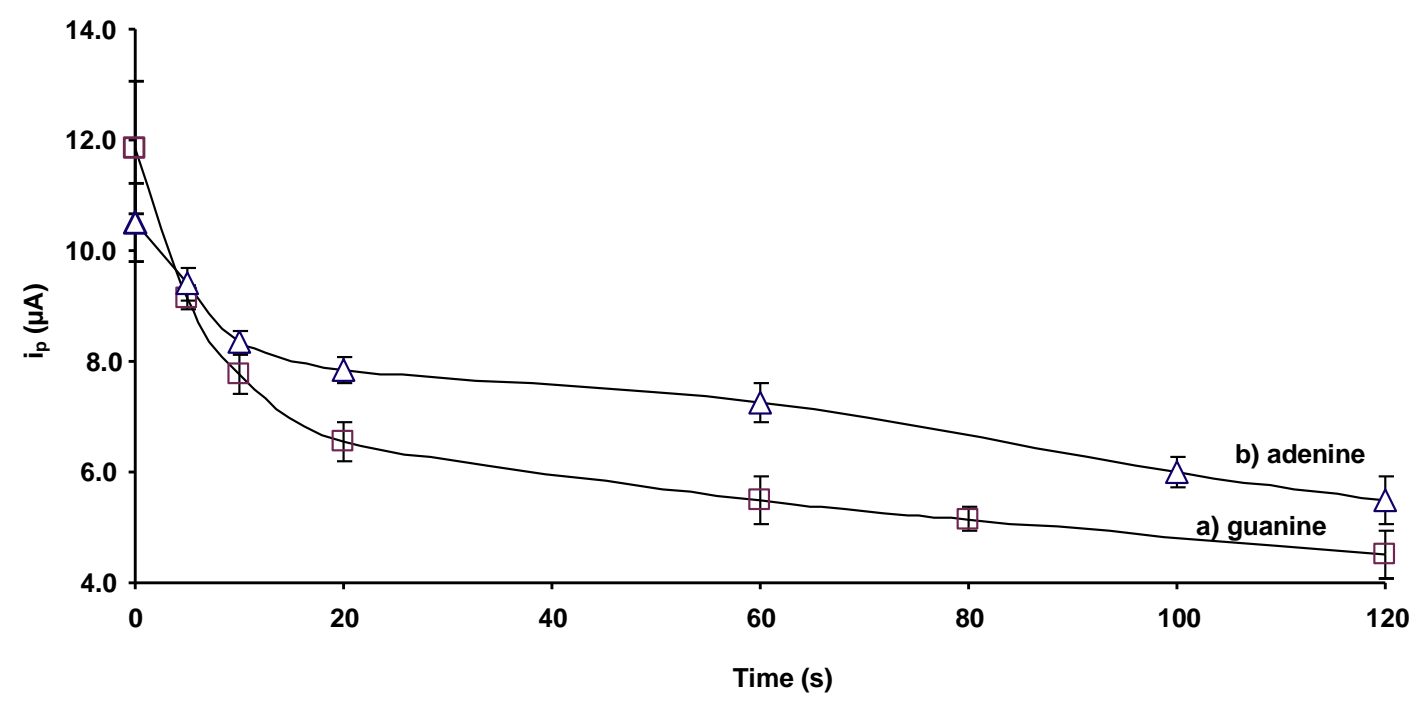

Fig. 2. Influence of incubation time of the biosensor with the current peak (a) $10 \mathrm{mg} \mathrm{L}^{-1}$ adenine base; (b) $3 \mathrm{mg} \mathrm{L} \mathrm{L}^{-1}$ guanine base.

when the $\mathrm{Fe}^{2+}$ was increased from $501 \mathrm{~mol} \mathrm{~L}^{-1}$ to $0.2 \mathrm{mmol} \mathrm{L}^{-1}$. At $\mathrm{Fe}^{2+}$ concentrations higher than $0.2 \mathrm{mmol} \mathrm{L}^{-1}$ the peak current remained essentially unchanged so, this concentration was chosen for the next experiments. At a guanine-biosensor, the increase of $\mathrm{Fe}^{2+}$ concentration promoted a decrease of $20-58 \%$ in the $i_{p}$. At $\mathrm{Fe}^{2+}$ concentration higher than $0.15 \mathrm{mmol} \mathrm{L}^{-1} i_{p}$ was achieved to remains unchanged, so this value was used for the next experiments. Reaction time between the hydroxyl radical and the DNA bases immobilized on the GCE surface depends on the half-life time of tne generatea Iree raaical, so tnıs parameter is an important reature to optimise. In this study the incubation time were ranged from 0 to 120 s. A $62 \%$ and a $53 \%$ decrease on the $i_{p}$ of guanine and adenine, respectively was observed after an incubation time of 120 s. Fig. 2 shows the correlation between the damage on the purine bases measured (correlated with the anodic peak current) and the incubation time. The incubation time of $120 \mathrm{~s}$ was chosen for both purinebased biosensors for all experiments.

\subsection{Determination of TAC}

Beverages, such as juice and infusions are an excellent source of exogenous antioxidants. Ine total pnenolic (IFU) reducing power and DPPH radical scavenging activity of these flavoured waters were determined using conventional optical methods. The polyphenols compounds were present in all flavoured water samples (0.5-359 mg of gallic acid $\left.\mathrm{L}^{-1}\right)$. The highest TPC levels were from citrus fruits (tangerine, lime and lemon) and from waters with tea, gingeng and gingko biloba. The reducing power values were ranged from ( 0.14 to $11.8 \mathrm{mg}$ gallic acid $\left.\mathrm{L}^{-1}\right)$ and $\mathrm{DPPH}$ radical scavenging activity $\left(0.29-211.5 \mathrm{mg}\right.$ trolox $\mathrm{L}^{-1}$ ) (Barroso, Noronha, Delerue-Matos, \& Oliveira, 2011). For the evaluation of the TAC of flavoured waters it was used the five antioxidants referred before. These antioxidants can be found in fruit, grapes, wine and teas. As expected, the anodic peak current of guanine and adenine immobilised on the GCE surface increased when the concentration of the antioxidant increased. The analytical parameters obtained in linearity studies between antioxidants concentration and peak current of purine-based biosensor are presented in Table 1.

Some authors reported the study of dsDNA (Korbut, Buckova, Labuda, \& Grundler, 2003; Liu, Roussel, Lagger, Tacchini, \& Girault, 2005; Mello et al., 2006), or ssDNA (Barroso, de-los-Santos-Álvarez et al., 2011a) or purine bases (Kamel et al., 2008) damage induced by hydroxyl radical, generated by the fenton system (Mello et al.,
Table 1

Analytical feature obtained for the 5 antioxidants standards.

\begin{tabular}{|c|c|c|c|c|c|}
\hline Parameters & $\begin{array}{l}\text { Ascorbic } \\
\text { acid }\end{array}$ & $\begin{array}{l}\text { Gallic } \\
\text { acid }\end{array}$ & $\begin{array}{l}\text { Caffeic } \\
\text { acid }\end{array}$ & $\begin{array}{l}\text { Coumaric } \\
\text { acid }\end{array}$ & Resveratrol \\
\hline \multicolumn{6}{|l|}{ Guanine-GCE } \\
\hline $\begin{array}{l}\text { Linear range } \\
\qquad\left(\mathrm{mg} \mathrm{L}^{-1}\right)\end{array}$ & $\begin{array}{l}0.50- \\
2.50\end{array}$ & $\begin{array}{l}0.10- \\
0.50\end{array}$ & $\begin{array}{l}0.40- \\
0.80\end{array}$ & $\begin{array}{l}0.31- \\
0.73\end{array}$ & $\begin{array}{l}0.10- \\
0.50\end{array}$ \\
\hline Slope $\left(1 \mathrm{~A} \mathrm{mg}^{-1} \mathrm{~L}\right)$ & 2.82 & 9.33 & 8.76 & 9.20 & 11.8 \\
\hline Intercept (1A) & 1.88 & 4.31 & 1.27 & 1.69 & 3.76 \\
\hline $\begin{array}{l}\text { Correlation } \\
\text { coefficient } \\
(n=5)\end{array}$ & 0.990 & 0.986 & 0.992 & 0.990 & 0.986 \\
\hline $\operatorname{RSD}(\%)\left(\mathrm{mg} \mathrm{L}^{-1}\right)$ & $\begin{array}{l}3.43 \\
(2.00)\end{array}$ & $\begin{array}{l}4.87 \\
(0.30)\end{array}$ & $\begin{array}{l}2.58 \\
(0.50)\end{array}$ & $\begin{array}{l}4.63 \\
(0.50)\end{array}$ & $\begin{array}{l}3.25 \\
(0.30)\end{array}$ \\
\hline $\operatorname{LOD}\left(\mathrm{mg} \mathrm{L}^{-1}\right)$ & 0.29 & 0.09 & 0.06 & 0.08 & 0.07 \\
\hline \multicolumn{6}{|l|}{ Adenine-GCE } \\
\hline $\begin{array}{l}\text { Linear range } \\
\qquad\left(\mathrm{mg} \mathrm{L}^{-1}\right)\end{array}$ & $\begin{array}{l}2.00- \\
6.00\end{array}$ & $\begin{array}{l}0.11- \\
0.44\end{array}$ & $\begin{array}{l}0.10- \\
0.50\end{array}$ & $\begin{array}{l}0.10- \\
1.00\end{array}$ & $\begin{array}{l}0.10- \\
0.50\end{array}$ \\
\hline Slope $\left(1 \mathrm{~A} \mathrm{mg}^{-1} \mathrm{~L}\right)$ & 0.40 & 7.38 & 11.9 & 3.81 & 8.78 \\
\hline Intercept (1A) & 5.08 & 5.30 & 2.08 & 4.35 & 3.81 \\
\hline $\begin{array}{l}\text { Correlation } \\
\text { coefficient } \\
(n=5)\end{array}$ & 0.983 & 0.986 & 0.990 & 0.972 & 0.972 \\
\hline $\operatorname{RSD}(\%)\left(\mathrm{mg} \mathrm{L}^{-1}\right)$ & $\begin{array}{l}2.45 \\
(3.00)\end{array}$ & $\begin{array}{l}5.35 \\
(0.30)\end{array}$ & $\begin{array}{l}4.86 \\
(0.30)\end{array}$ & $\begin{array}{l}7.56 \\
(0.50)\end{array}$ & $\begin{array}{l}6.35 \\
(0.30)\end{array}$ \\
\hline $\mathrm{LOD}\left(\mathrm{mg} \mathrm{L}^{-1}\right)$ & 0.99 & 0.08 & 0.07 & 0.27 & 0.10 \\
\hline
\end{tabular}

$\operatorname{RSD}(\%)=r /[\text { antioxidant }]_{\text {mean found }} X 100$

2006) or UV radical (Liu et al., 2005) and its protection with the ascorbic acid (Kamel et al., 2008) gallic acid (Liu et al., 2005) and flavonoids (Korbut et al., 2003). Zhang et al. (2008) reported the study of DNA damage induced by Fenton system on a GCE and its protection with the antioxidant ascorbic acid. Ascorbic acid promoted protective effect on the DNA in a narrow concentration range (from 1.5 to $2.5 \mathrm{mmol} \mathrm{l}^{-1}$ ) (Zhang et al., 2008). Nobushi and Uchikura (2010) reported the protective effects on the DNA by applying ascorbic acid as a scavenging antioxidant. Enzymemodified electrodes using ascorbate oxidase and peroxidase enzymes for the detection of ascorbic acid showed linear ranges in the submM level (Mello \& Kubota, 2007).

The purine-based biosensors were applied to the evaluation of TAC of flavours and flavoured waters. Table 2 shows the TAC values expressed in $\mathrm{mg} \mathrm{L}^{-1}$ of ascorbic acid, gallic acid, caffeic acid, coumaric acid and resveratrol. It was verified that all flavours and flavoured waters presented antioxidant capacity. Like it was expected 


\begin{tabular}{|c|c|c|c|c|c|c|c|c|c|c|c|}
\hline \multirow[t]{3}{*}{ Brand } & \multirow[t]{3}{*}{ Sample } & \multicolumn{5}{|c|}{ Guanine-biosensor } & \multicolumn{5}{|c|}{ Adenine-biosensor } \\
\hline & & Ascorbic acid & Gallic acid & Caffeic acid & Coumaric acid & Resveratrol & Ascorbic acid & Gallic acid & Caffeic acid & Coumaric acid & Resveratrol \\
\hline & & \multicolumn{10}{|l|}{$\mathrm{mg} \mathrm{L}^{-1}$} \\
\hline \multirow[t]{6}{*}{ Flavour } & Lemon & $120.23 \pm 11.48$ & $10.30 \pm 3.47$ & $45.67 \pm 3.69$ & $38.92 \pm 3.52$ & $12.81 \pm 2.74$ & $526.45 \pm 35.62$ & $32.52 \pm 1.92$ & $30.42 \pm 1.19$ & $35.43 \pm 3.71$ & $21.53 \pm 1.62$ \\
\hline & Tangerine & $173.56 \pm 27.61$ & $26.41 \pm 8.34$ & $62.84 \pm 8.89$ & $55.27 \pm 8.46$ & $25.55 \pm 6.60$ & $375.31 \pm 25.45$ & $16.94 \pm 2.93$ & $25.38 \pm 2.57$ & $19.69 \pm 2.75$ & $14.69 \pm 3.87$ \\
\hline & Apple & $185.64 \pm 5.77$ & $30.06 \pm 1.74$ & $66.72 \pm 1.86$ & $58.97 \pm 1.77$ & $28.43 \pm 1.38$ & $476.83 \pm 16.69$ & $16.30 \pm 1.97$ & $28.76 \pm 1.22$ & $30.26 \pm 3.82$ & $19.28 \pm 1.66$ \\
\hline & Strawberry & $126.26 \pm 19.58$ & $12.12 \pm 5.91$ & $47.61 \pm 6.30$ & $40.77 \pm 6.00$ & $14.24 \pm 4.68$ & $309.82 \pm 7.87$ & $20.87 \pm 2.68$ & $23.19 \pm 1.66$ & $12.86 \pm 1.87$ & $11.73 \pm 2.26$ \\
\hline & Gooseberry & $100.82 \pm 10.03$ & $9.18 \pm 1.03$ & $39.16 \pm 3.22$ & $32.72 \pm 3.07$ & $7.97 \pm 2.40$ & $211.59 \pm 17.82$ & $15.58 \pm 0.96$ & $19.92 \pm 0.59$ & $10.50 \pm 0.06$ & $10.71 \pm 0.81$ \\
\hline & Lime & $102.62 \pm 11.33$ & $10.97 \pm 2.42$ & $40.00 \pm 3.65$ & $33.52 \pm 3.47$ & $8.59 \pm 2.71$ & $571.91 \pm 13.45$ & $14.64 \pm 2.29$ & $31.94 \pm 4.52$ & $40.17 \pm 10.12$ & $23.58 \pm 6.13$ \\
\hline \multirow[t]{4}{*}{ A } & 1 Lemon & $12.27 \pm 0.69$ & $2.27 \pm 0.29$ & $4.34 \pm 0.23$ & $3.88 \pm 0.22$ & $2.05 \pm 0.17$ & $18.33 \pm 2.59$ & $1.38 \pm 0.16$ & $1.26 \pm 0.09$ & $4.06 \pm 0.31$ & $0.71 \pm 0.12$ \\
\hline & 2 Mango & $9.53 \pm 0.70$ & $1.44 \pm 0.09$ & $3.45 \pm 0.15$ & $3.04 \pm 0.04$ & $1.40 \pm 0.05$ & $7.42 \pm 3.61$ & $0.51 \pm 0.02$ & $0.87 \pm 0.02$ & $2.36 \pm 0.04$ & $0.21 \pm 0.06$ \\
\hline & 3 Strawberry & $3.46 \pm 0.41$ & - & $1.50 \pm 0.13$ & $1.18 \pm 0.13$ & - & $7.21 \pm 0.76$ & $0.43 \pm 005$ & $0.93 \pm 0.03$ & $2.21 \pm 0.07$ & $0.20 \pm 0.03$ \\
\hline & 4 Natural & - & - & - & - & - & - & - & - & - & - \\
\hline \multirow[t]{3}{*}{ B } & 5 Pineapple/orange & $5.42 \pm 0.52$ & $0.20 \pm 0.02$ & $2.13 \pm 0.10$ & $1.78 \pm 0.13$ & $0.42 \pm 0.09$ & $37.54 \pm 1.97$ & $0.18 \pm 0.06$ & $1.92 \pm 0.07$ & $1.73 \pm 0.11$ & $1.57 \pm 0.09$ \\
\hline & 6 Lemon & $5.13 \pm 0.28$ & $0.11 \pm 0.08$ & $2.04 \pm 0.09$ & $1.69 \pm 0.08$ & $0.35 \pm 0.07$ & $34.06 \pm 5.69$ & - & $1.72 \pm 0.19$ & $1.56 \pm 0.05$ & $1.41 \pm 0.26$ \\
\hline & 7 Natural & - & - & - & - & - & - & - & - & - & - \\
\hline \multirow[t]{4}{*}{$\mathrm{c}$} & 8 Lemon/magnesium & $8.26 \pm 0.28$ & $1.06 \pm 0.06$ & $3.04 \pm 0.05$ & $2.65 \pm 0.09$ & $1.09 \pm 0.06$ & $22.66 \pm 1.19$ & $0.11 \pm 0.05$ & $1.49 \pm 0.04$ & $1.59 \pm 0.10$ & $0.90 \pm 0.05$ \\
\hline & 9 Apple/white tea & $6.99 \pm 0.14$ & $0.67 \pm 0.04$ & $2.63 \pm 0.04$ & $2.26 \pm 0.04$ & $0.79 \pm 0.03$ & $4.16 \pm 0.67$ & $0.41 \pm 0.05$ & $0.86 \pm 0.02$ & $2.17 \pm 0.02$ & $0.60 \pm 0.03$ \\
\hline & 10 Pineapple/fibre & $6.41 \pm 0.15$ & $0.50 \pm 0.13$ & $2.44 \pm 0.17$ & $2.08 \pm 0.13$ & $0.65 \pm 0.02$ & $13.71 \pm 5.52$ & $0.21 \pm 0.02$ & $1.30 \pm 0.18$ & $1.78 \pm 0.04$ & $0.49 \pm 0.05$ \\
\hline & 11 Natural & - & - & - & - & - & - & - & - & - & - \\
\hline \multirow[t]{4}{*}{ D } & 12 Apple & $4.64 \pm 0.69$ & - & $1.88 \pm 0.22$ & $1.54 \pm 0.21$ & $0.23 \pm 0.06$ & $5.43 \pm 0.96$ & & $0.84 \pm 0.07$ & $2.25 \pm 0.16$ & $0.12 \pm 0.02$ \\
\hline & 13 Orange/peach & $4.59 \pm 0.35$ & - & $1.86 \pm 0.11$ & $1.52 \pm 0.11$ & $0.22 \pm 0.08$ & $3.02 \pm 0.09$ & - & $0.75 \pm 0.08$ & $1.52 \pm 0.05$ & - \\
\hline & 14 Lemon & $4.74 \pm 0.28$ & - & $1.91 \pm 0.08$ & $1.57 \pm 0.04$ & $0.25 \pm 0.05$ & $3.34 \pm 0.08$ & - & $0.84 \pm 0.03$ & $1.81 \pm 0.08$ & - \\
\hline & 15 Natural & - & - & - & - & - & - & - & - & - & - \\
\hline \multirow[t]{5}{*}{$\mathrm{E}$} & 16 Lemon & $7.57 \pm 0.29$ & $0.85 \pm 0.06$ & $2.82 \pm 0.19$ & $2.44 \pm 0.32$ & $0.93 \pm 0.06$ & $19.14 \pm 2.41$ & $1.37 \pm 0.13$ & $1.29 \pm 0.08$ & $4.02 \pm 0.26$ & $0.74 \pm 0.11$ \\
\hline & 17 Orange/raspberry & $2.98 \pm 0.41$ & - & $1.50 \pm 0.14$ & $1.18 \pm 0.13$ & - & $4.23 \pm 0.25$ & $0.52 \pm 0.10$ & $0.88 \pm 0.04$ & $2.39 \pm 0.20$ & $0.70 \pm 0.06$ \\
\hline & 18 Peach/pineapple & $3.86 \pm 0.14$ & - & $1.63 \pm 0.04$ & $1.30 \pm 0.05$ & - & $11.78 \pm 6.15$ & $0.34 \pm 0.05$ & $1.25 \pm 0.21$ & $2.02 \pm 0.10$ & $0.41 \pm 0.02$ \\
\hline & 19 Guava/lime & $3.66 \pm 0.70$ & - & $1.56 \pm 0.07$ & $1.24 \pm 0.32$ & - & $3.96 \pm 0.18$ & $0.11 \pm 0.05$ & $1.01 \pm 0.24$ & $1.59 \pm 0.10$ & - \\
\hline & 20 Natural & - & - & - & - & - & - & - & - & - & - \\
\hline \multirow[t]{6}{*}{$\mathrm{F}$} & 21 Lemon/green tea & $9.83 \pm 0.28$ & $1.53 \pm 0.04$ & $3.55 \pm 0.91$ & $3.13 \pm 0.09$ & $1.47 \pm 0.07$ & $15.94 \pm 0.86$ & $0.34 \pm 0.05$ & $1.26 \pm 0.03$ & $2.03 \pm 0.14$ & $0.60 \pm 0.04$ \\
\hline & 22 Raspberry/ginseng & $8.90 \pm 0.35$ & $1.25 \pm 0.10$ & $3.25 \pm 0.11$ & $2.84 \pm 0.10$ & $1.25 \pm 0.08$ & $27.36 \pm 1.28$ & $0.28 \pm 0.08$ & $1.59 \pm 0.04$ & $1.92 \pm 0.15$ & $1.11 \pm 0.06$ \\
\hline & $23 \mathrm{Peach} /$ white tea & $6.89 \pm 0.28$ & $0.64 \pm 0.03$ & $2.60 \pm 0.09$ & $2.23 \pm 0.08$ & $0.77 \pm 0.06$ & $28.49 \pm 1.16$ & $0.39 \pm 0.04$ & $1.63 \pm 0.04$ & $2.14 \pm 0.15$ & $1.16 \pm 0.05$ \\
\hline & 24 Mango/ginkgo beloba & $7.48 \pm 0.08$ & $0.82 \pm 0.05$ & $2.79 \pm 0.05$ & $2.41 \pm 0.08$ & $0.91 \pm 0.02$ & $19.33 \pm 1.97$ & $0.49 \pm 0.02$ & $1.40 \pm 0.07$ & $2.32 \pm 0.04$ & $0.75 \pm 0.09$ \\
\hline & 25 Melon/mint & $8.58 \pm 0.38$ & $1.16 \pm 0.11$ & $3.15 \pm 0.03$ & $2.75 \pm 0.12$ & $1.17 \pm 0.11$ & $24.89 \pm 1.97$ & $0.41 \pm 0.05$ & $1.49 \pm 0.07$ & $2.17 \pm 0.07$ & $1.00 \pm 0.08$ \\
\hline & 26 Natural & - & - & - & - & - & - & - & - & - & - \\
\hline \multirow[t]{5}{*}{ G } & 27 Lemon & $7.47 \pm 0.20$ & $0.82 \pm 0.06$ & $2.79 \pm 0.06$ & $2.40 \pm 0.06$ & $0.91 \pm 0.05$ & $29.77 \pm 0.96$ & $2.02 \pm 0.21$ & $1.73 \pm 0.03$ & $5.29 \pm 0.41$ & $1.22 \pm 0.04$ \\
\hline & 28 Lime & $4.11 \pm 0.06$ & - & $1.71 \pm 0.02$ & $1.37 \pm 0.02$ & $0.10 \pm 0.01$ & $5.42 \pm 1.98$ & - & $0.94 \pm 0.07$ & $0.76 \pm 0.03$ & $0.12 \pm 0.08$ \\
\hline & 29 Apple & $7.48 \pm 0.28$ & $0.82 \pm 0.09$ & $2.79 \pm 0.10$ & $2.41 \pm 0.08$ & $0.91 \pm 0.07$ & $45.05 \pm 2.95$ & $1.20 \pm 0.21$ & $2.28 \pm 0.09$ & $3.70 \pm 0.05$ & $1.91 \pm 0.13$ \\
\hline & 30 Peach & $9.14 \pm 0.57$ & $1.33 \pm 0.13$ & $3.33 \pm 0.15$ & $2.92 \pm 0.13$ & $1.31 \pm 0.10$ & $14.25 \pm 2.65$ & $0.79 \pm 0.16$ & $1.12 \pm 0.08$ & $2.90 \pm 0.31$ & $0.51 \pm 0.02$ \\
\hline & 31 Natural & - & - & - & - & - & - & - & - & - & - \\
\hline \multirow[t]{2}{*}{$\mathrm{H}$} & 32 Lemon & $6.38 \pm 0.39$ & $0.49 \pm 0.07$ & $2.44 \pm 0.07$ & $2.07 \pm 0.12$ & $0.65 \pm 0.09$ & $18.43 \pm 1.27$ & $0.09 \pm 0.01$ & $1.35 \pm 0.04$ & $1.54 \pm 0.03$ & $0.71 \pm 0.06$ \\
\hline & 33 Natural & - & - & - & - & - & - & - & - & - & - \\
\hline \multirow[t]{4}{*}{ I } & 34 Lemon & $34.62 \pm 1.97$ & $0.63 \pm 0.03$ & $1.91 \pm 0.07$ & $2.59 \pm 0.56$ & $1.44 \pm 0.09$ & $34.62 \pm 1.97$ & $0.63 \pm 0.03$ & $1.91 \pm 0.07$ & $2.59 \pm 0.56$ & $1.44 \pm 0.09$ \\
\hline & 35 Green Apple & $37.40 \pm 1.69$ & $0.92 \pm 0.14$ & $2.00 \pm 0.07$ & $3.15 \pm 0.26$ & $1.57 \pm 0.02$ & $37.40 \pm 1.69$ & $0.92 \pm 0.14$ & $2.00 \pm 0.07$ & $3.15 \pm 0.26$ & $1.57 \pm 0.02$ \\
\hline & 36 Strawberry & $40.32 \pm 2.78$ & $0.14 \pm 0.03$ & $2.07 \pm 0.03$ & - & $1.70 \pm 0.04$ & $40.32 \pm 2.78$ & $0.14 \pm 0.03$ & $2.07 \pm 0.03$ & - & $1.70 \pm 0.04$ \\
\hline & 37 Natural & - & - & - & - & - & - & - & - & - & - \\
\hline \multirow[t]{2}{*}{$\mathrm{j}$} & 38 Lemon & $5.71 \pm 0.09$ & $0.29 \pm 0.04$ & $2.22 \pm 0.09$ & $1.86 \pm 0.05$ & $0.48 \pm 0.04$ & $36.35 \pm 2.47$ & $0.69 \pm 0.13$ & $1.86 \pm 0.15$ & $2.90 \pm 0.25$ & $1.52 \pm 0.11$ \\
\hline & 39 Natural & - & - & - & - & - & - & - & - & - & - \\
\hline
\end{tabular}


the natural waters not presented antioxidant capacity. Flavours presented the highest TAC values, as demonstrated by results in Table 2. Indeed, flavours are fruit extract and have in its composition several concentrated antioxidant compounds, so the higher TAC values were expected. Using the guanine and adenine-biosensor the higher TAC values were found with the antioxidant standard ascorbic acid. When it was used the guanine-based biosensor, the flavour that presented the highest TAC value was apple, followed by tangerine, strawberry, lemon, gooseberry and lime. At the adenine-GCE lime was the flavour that presented the highest TAC value followed by lemon, apple, tangerine, strawberry and gooseberry.

When the guanine-biosensor was applied to the quantification of TAC in flavoured waters, TAC values ranged from 2.98 to $40.32 \mathrm{mg} \mathrm{L}^{-1} ; 0.11$ to $2.27 \mathrm{mg} \mathrm{L}^{-1} ; 1.50$ to $4.34 \mathrm{mg} \mathrm{L}^{-1}, 1.18$ to $3.88 \mathrm{mg} \mathrm{L}^{-1}, 0.10$ to $2.05 \mathrm{mg} \mathrm{L}^{-1}$ with the antioxidant ascorbic acid, gallic acid, caffeic acid, coumaric acid and resveratrol, respectively. Using ascorbic acid as standard antioxidant, lemon flavoured waters presented the highest TAC values on all brands (except in brand I). The highest TAC values was found in brand I (samples 34-36) followed by brand $F$ (samples 21-25) brand G (samples 27-30) and sample C (samples 8-10). Using the gallic acid as a standard antioxidant some flavoured waters not presented antioxidant activity such as brand D (samples 12-14) brand E (samples 17-19) sample 3 (brand A), and sample 28 (brand G). The lowest TAC value was from the brand B and the highest was from brand F. With the caffeic acid standard antioxidant all flavoured waters presented antioxidant capacity. The highest TAC values were from brand $\mathrm{F}$ following brand $\mathrm{A}$ and brand $\mathrm{C}$. Using the coumaric acid and the resveratrol as standard antioxidant some samples not presented antioxidant activity, such as, sample 36 (brand I) with coumaric acid and sample 3 (brand A), sample 17, sample 18 and sample 19 (brand E) with the resveratrol antioxidant. TAC values obtained with the four antioxidant, gallic acid, caffeic acid, coumaric acid and resveratrol are narrower than the values obtained with the standard ascorbic acid antioxidant. Theses differences obtained between the ascorbic acid and the others antioxidants can be elucidated by the fact that ascorbic acid presented a larger linear range $\left(0.50-2.50 \mathrm{mg} \mathrm{L}^{-1}\right)$.

When it was used the adenine-GCE, the highest TAC contents were found with the ascorbic acid antioxidant. With this antioxidant, TAC values ranged between 3.02 and $45.05 \mathrm{mg} \mathrm{L}^{-1}$ of ascorbic acid. The highest TAC values were obtained in brand I, followed from brand J, brand B, brand F and brand G. The lowest TAC value was obtained in brand D. When it was used the gallic acid antioxidant, some flavoured waters not presented antioxidant activity, such as brand D (samples 12-14), and sample 28 (brand G). TAC values ranged from 0.09 to $2.02 \mathrm{mg} \mathrm{L}^{-1}$ of gallic acid. The highest TAC value was found on brand G (samples 27 and 29) following brand $\mathrm{E}$ and brand $\mathrm{A}$. The lowest TAC value was found in brand $\mathrm{H}$ followed by brand $\mathrm{B}$, brand $\mathrm{C}$ and brand $\mathrm{F}$. With the caffeic acid antioxidant all flavoured waters presented antioxidant activity and the TAC values ranged from 0.75 to $2.28 \mathrm{mg} \mathrm{L}^{-1}$. When it was used the coumaric acid and the resveratrol as standard antioxidant some flavoured waters not presented antioxidant activity, such as sample 36 with the coumaric acid antioxidant and sample 13, sample 14 and sample 19 with the resveratrol antioxidant. TAC values ranged between $0.76-5.29$ and $0.12-1.57 \mathrm{mg} \mathrm{L}^{-1}$ when it was used coumaric acid and resveratrol respectively. Like it was happened with the guanine-biosensor, larger TAC values were obtained with the ascorbic acid and the other four antioxidants presented a narrow TAC range. Analysing results from Table 2 is possibly to confirm that the purine bases immobilized on GCE can be used for the quantification of TAC in beverages, however using the adenine-GCE and ascorbic acid as antioxidant standard it was obtained the highest TAC values.

\section{Conclusion}

A guanine-biosensor and adenine-biosensor for the TAC quantification of beverages was used. The electroanalytical technique is based on the interaction of adenine or guanine immobilized on the GCE surface with the hydroxyl radical. The hydroxyl radical had the capacity to damage the purine base. Five antioxidants (ascorbic acid, gallic acid, caffeic acid, coumaric acid and resveratrol) were tested as hydroxyl radicals scangers exihiting efficiencies ranging from $47 \%$ to $79 \%$. The protective effect on the DNA bases performed by the presence of these antioxidants allowed the evaluation of TAC in food samples. Ascorbic acid presented the highest TAC values and seems to be the most sensitive standard antioxidant. The purine-based biosensor developed is disposable, and requires a very easy, rapid, reproducible preparation and also the advantage to combine with portable equipment.

\section{Acknowledgements}

M. Fátima Barroso is grateful to Fundação para a Ciência e a Tecnologia for a Ph.D. grant (SFRH/BD/ 29440/2006). The authors thank Frize for providing flavours samples.

\section{References}

Barroso, M. F., Delerue-Matos, C., \& Oliveira, M. B. P. P. (2011a). Electrochemical DNA-sensor for evaluation of total antioxidant capacity of flavours and flavoured waters using superoxide radical damage. Biosensor $\mathcal{E}$ Bioelectronics, 26(9), 3748-3754.

Barroso, M. F., de-los-Santos-Álvarez, N., Lobo-Castañón, M. J., Miranda-Ordieres, A. J., Delerue-Matos, C., Oliveira, M. B. P. P., et al. (2011a). DNA-based biosensor for the electrocatalytic determination of antioxidant capacity in beverages. Biosensors \& Bioelectronics, 26(5), 2396-2401.

Barroso, M. F., de-los-Santos-Álvarez, N., Lobo-Castañón, M. J., Miranda-Ordieres, A. J., Delerue-Matos, C., Oliveira, M. B. P. P., et al. (2011b). Electrocatalytic evaluation of DNA damage by superoxide Radical for antioxidant capacity assessment. Journal of Electroanalytical Chemistry, 659(1), 43-49.

Barroso, M. F., Delerue-Matos, C., \& Oliveira, M. B. P. P. (2011b). Evaluation of the total antioxidant capacity of flavored water and electrochemical purine damage by sulfate radicals using a purine-based sensor. Electrochimica Acta, 56(24), 8954-8961.

Barroso, M. F., Noronha, J. P., Delerue-Matos, C., \& Oliveira, M. P. P. (2011). Flavored waters: Influence of ingredients on antioxidant capacity and terpenoid profile by HS-SPME/GC-MS. Journal of Agricultural and Food Chemistry, 59(9), 50625072 .

Buettner, G. R. (1993). The pecking order of free-radicals and antioxidants - Lipidperoxidation, alpha-tocopherol, and ascorbate. Archives of Biochemistry and Biophysics, 300(2), 535-543.

Cadet, J., Douki, T., Gasparutto, D., \& Ravanat, J.-L. (2003). Oxidative damage to DNA: Formation, measurement and biochemical features. Mutation Research Fundamental and Molecular Mechanisms of Mutagenesis Mutation Research, 531(12), 5-23.

Dizdaroglu, M., Jaruga, P., Birincioglu, M., \& Rodriguez, H. (2002). Free radicalinduced damage to DNA: Mechanisms and measurement. Free Radical Biology and Medicine, 32(11), 1102-1115.

Frankel, E. N. (2007). Antioxidants in food and biology facts and fiction, Vol. 20. Bridgwater, England: Publisher Oily Press.

Halliwell, B., Gutteridge, J. M., \& Cross, C. E. (1992). Free radicals, antioxidants, and human disease: Where are we now. Journal of Laboratory and Clinical Medicine, 119(6), 598-620.

Ignat, I., Volf, I., \& Popa, V. I. (2011). A critical review of methods for characterisation of polyphenolic compounds in fruits and vegetables. Food Chemistry, 126, 18211835.

Jaitz, L., Siegl, K., Eder, R., Rak, G., Abranko, L., Koellensperger, G., et al. (2010). LCMS/MS analysis of phenols for classification of red wine according to geographic origin, grape variety and vintage. Food Chemistry, 122, 366-372.

Jaruga, P., \& Dizdaroglu, M. (1996). Repair of products of oxidative DNA base damage in human cells. Nucleic Acids Research, 24(8), 1389-1394.

Kamel, A. H., Moreira, F. T. C., Delerue-Matos, C., \& Sales, M. G. F. (2008). Electrochemical determination of antioxidant capacities in flavored waters by guanine and adenine biosensors. Biosensors and Bioelectronics, 24(4), 591-599. Korbut,

O., Buckova, M., Labuda, J., \& Grundler, P. (2003). Voltammetric detection of antioxidative properties of flavonoids using electrically heated DNA modified carbon paste electrode. Sensors, 3(1), 1-10.

Lee, W., Davis, K. A., Rettmer, R. L., \& Lable, R. F. (1988). Ascorbic-acid status Biochemical and clinical considerations. American Journal of Clinical Nutrition, 48(2), 289-290. 
Liu, J., Roussel, C., Lagger, G., Tacchini, P., \& Girault, H. H. (2005). Antioxidant sensors based on DNA-modified electrodes. Analytical Chemistry, 77(23), 7687 7694 .

Mello, L. D., Hernandez, S., Marrazza, G., Mascini, M., \& Kubota, L. T. (2006). Investigations of the antioxidant properties of plant extracts using a DNAelectrochemical biosensor. Biosensors \& Bioelectronics, 21(7), 1374-1382.

Mello, L. D., \& Kubota, L. T. (2007). Biosensors as a tool for the antioxidant status evaluation. Talanta, 72(2), 335-348.

Nobushi, Y., \& Uchikura, K. (2010). Selective detection of hydroxyl radical scavenging capacity based on electrogenerated chemiluminescence detection using tris $\left(2,2^{0}\right.$-bipyridine)ruthenium(III) by flow injection analysis. Chemical $\mathcal{E}$ Pharmaceutical Bulletin, 58(1), 117-120.

Piljac-Ž egarac, J., Valek, L., Stipc evic', T., \& Martinez, S. (2010). Electrochemical determination of antioxidant capacity of fruit tea infusions. Food Chemistry, 121, $820-825$.

Rice, M. E., Galus, Z., \& Adams, R. N. (1983). Graphite paste electrodes. Effects of paste composition and surface states on electron-tranfer rates. Journal of Electroanalytical Chemistry, 143(1-2), 89-102.

Rice-Evans, C. (2001). Flavonoid antioxidants. Current Medicinal Chemistry, 8(7), $797-807$.
Sanchez-Moreno, C. (2002). Review: Methods used to evaluate the free radical scavenging activity in foods and biological systems. Food Science and Technology International, 8(3), 121-137.

Sassolas, A., Leca-Bouvier, B. D., \& Blum, L. J. (2008). DNA biosensors and microarrays. Chemical Reviews, 108(1), 109-139.

Smirnoff, N. (2000). Ascorbic acid: Metabolism and functions of a multi-facetted molecule. Current Opinion in Plant Biology, 3(3), 229-235.

Soobrattee, M. A., Neergheen, U. S., Ramma, A. L., Aruoma, O. I., \& Bahorun, T. (2005). Phenolics as potential antioxidant therapeutic agents: Mechanism and actions. Mutation Research-Fundamental and Molecular Mechanisms of Mutagenesis, 579(12), 200-213.

Thavasi, V., Leong, L. P. \& Bettens, R. P. A. (2006). Investigation of the influence of hydroxy groups on the radical scavenging ability of polyphenols. Journal of Physical Chemistry A, 110(14), 4918-4923.

Vertuani, S., Angusti, A., \& Manfredini, S. (2004). The antioxidant and proantioxidants: An overview. Current Pharmaceutical Design, 10(14), 1677-1694.

Zhang, J. J., Wang, B., Li, Y. F., Jia, W. L., Cui, H., \& Wang, H. S. (2008). Electrochemical study on DNA damage based on the direct oxidation of 8-hydroxydeoxygu anosine at an electrochemically modified glassy carbon electrode. Electroanalysis, 20(15), 1684-1689. 